\title{
Morphological Control of Carbon-Supported Pt-Based Nanoparticles via One-Step Synthesis
}

Tatsuichiro Nakamoto $^{\text {a }}$, Ryohei Seki ${ }^{\mathrm{b}}$, Ken-ichi Motomiya ${ }^{\mathrm{a}}$, Shun Yokoyama ${ }^{\mathrm{a}}$, Kazuyuki Tohji ${ }^{\text {a }}$ and Hideyuki Takahashi ${ }^{\text {a }}$

${ }^{a}$ Graduate School of Environmental Studies, Tohoku University, Sendai, Miyagi 980-8579, Japan

${ }^{\mathrm{b}}$ Manufacturing Innovation Division, Panasonic Corporation, Kadoma, Osaka 571-8502, Japan

The morphology of Pt-based nanoparticles supported on carbon is controlled to enhance the oxygen reduction reaction (ORR) catalytic performance. Herein a simple one-step method without a polymer surfactant is demonstrated to synthesize $\mathrm{Pt}-\mathrm{Cu}$ nanoclusters, $\mathrm{Pt}-\mathrm{Cu}$ nanospheres, and $\mathrm{Cu}$-doped $\mathrm{Pt}$ nanoplates. Metal precursors are reduced in a $\mathrm{NaCl}$ or $\mathrm{NH}_{4} \mathrm{Cl}$ aqueous solution containing carbon supports, and nanoparticles are directly deposited on carbon. $\mathrm{Cl}^{-}$ions generated from $\mathrm{NaCl}$ or $\mathrm{NH}_{4} \mathrm{Cl}$ behave as oxidative etchants when $\mathrm{O}_{2}$ is dissolved in the synthesis solution, delaying the reduction of metal ions and leading to larger particles. Nanoclusters are obtained in the absence of $\mathrm{Cl}^{-}$ions. In addition, $\mathrm{NH}_{4}{ }^{+}$guides the growth direction of $\mathrm{Pt}$ in the presence of oxidative etchants, forming a plate-like morphology that exposes the $\{111\}$ facets. Half-cell measurements are performed in acidic media to evaluate the electrochemical properties. $\mathrm{Cu}$-doped $\mathrm{Pt}$ nanoplates exhibit a 3.67-times higher ORR catalytic activity than the commercial Pt catalysts thanks to the synergistic effect with a small amount of $\mathrm{Cu}$ and selective exposure of the $\{111\}$ facets. The result suggests that transition metals in Pt-based electrocatalysts may be unnecessary to form intermetallic alloyed crystals for the enhanced ORR performance.

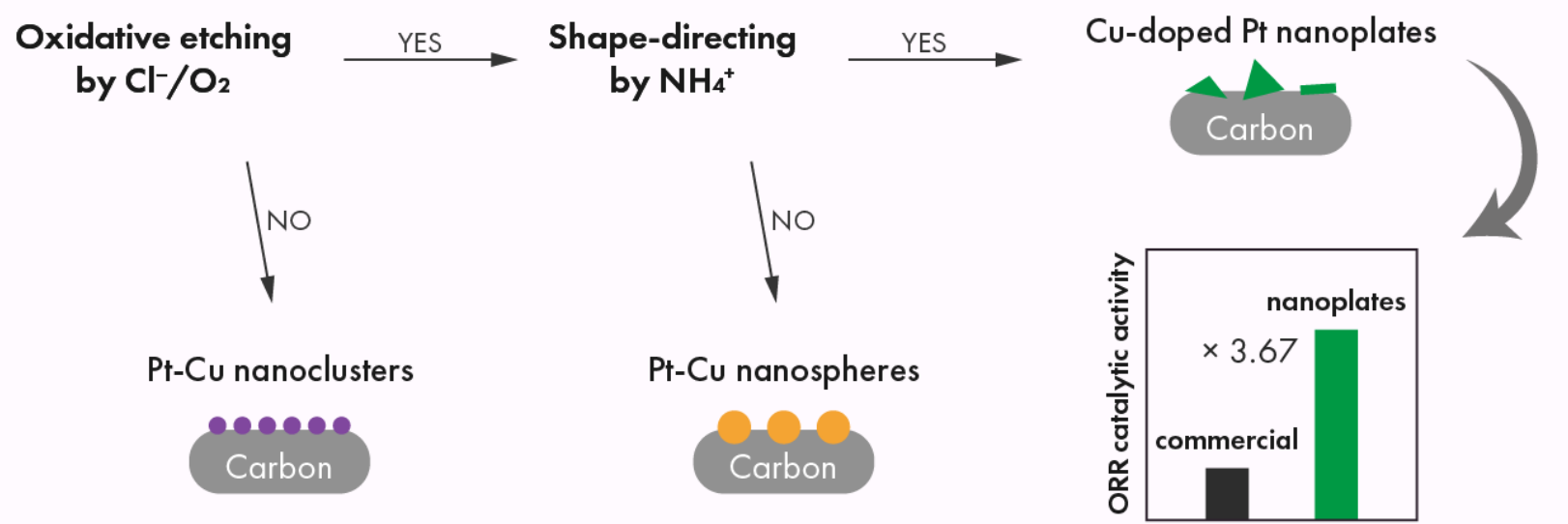




\section{Introduction}

Proton-exchange membrane (PEM) fuel cells, which can provide clean, highly efficient electricity, are essential to improve the sustainability of our society. Since the sluggish kinetics of the oxygen reduction reaction (ORR) determine the performance of PEM fuel cells, precious Pt catalysts are crucial in the cathode electrode $(1,2)$. To date, great efforts have been undertaken to reduce the Pt loading by enhancing the ORR catalytic performance. The most widely accepted and successful strategy is to combine $\mathrm{Pt}$ with inexpensive transition metals such as $\mathrm{Fe}, \mathrm{Co}, \mathrm{Ni}$, or $\mathrm{Cu}$ to form $\mathrm{Pt}$ based alloys (3-10). The formation of Pt-based alloys modifies the electronic structure on the surface of catalytic particles and improves the ORR catalytic performance (11-14). The difference in the atomic radius induces surface strain, which can also contribute to the electrochemical properties (11, 15). Among the various transition metals, $\mathrm{Cu}$ is regarded as one of the best candidates due to its abundance, low cost, and good catalytic properties $(5,7,8,10)$. Another promising strategy is to control the shape of the catalytic particles. Previous studies have shown that the catalytic activities depend on the crystal facets, which can be manipulated by the shape of catalytic particles (16-19). In addition, shape-controlled catalytic particles with a higher density of steps and edges on the surface are more active than spherical ones $(20,21)$.

During the past few decades, a variety of Pt-based nanoparticles with different shapes (plates, polyhedrons, multipods, etc.) have been synthesized to enhance the ORR catalytic performance (1619). However, the reported methods for the shape control postulate polymer surfactants and complicated processes, which are undesirable for practical use. To control the growth direction and to obtain anisotropic shapes, which are thermodynamically unfavored, polymer capping agents are widely used with oxidative etchant $(22,23)$, but they often inhibit the ORR by remaining on the surface (24). Moreover, most of the shape-controlled nanoparticles are synthesized through plural or seed-mediated reactions to introduce stacking faults or twin defects into the nuclei of the nanoparticles (22). After the synthesis of catalytic nanoparticles, additional deposition process is also required because nanoparticles need to be deposited on carbon supports for the use as electrocatalysts $(25,26)$. Therefore, a simple method that alleviates the need for polymer surfactants and complicated processes to prepare carbon-support nanoparticles with controlled shapes is highly desired.

Herein we propose a facile and simple aqueous phase method for morphological control of Pt-based nanoparticles supported on carbon. The present method provides a true one-step synthesis of Pt-based electrocatalysts with controlled shapes. $\mathrm{Pt}$ and $\mathrm{Cu}$ precursors are simply reduced together in the presence of a carbon support in an aqueous solution $\mathrm{NH}_{4} \mathrm{Cl}$ or $\mathrm{NaCl}$ but without adding a polymer capping agent or a dispersing agent. This method successfully synthesized Pt-Cu nanoclusters, $\mathrm{Pt}-\mathrm{Cu}$ nanospheres, and $\mathrm{Cu}$-doped $\mathrm{Pt}$ nanoplates supported on carbon. The $\mathrm{Cu}$-doped $\mathrm{Pt}$ nanoplates exhibit the highest ORR performance among the synthetic and the commercial catalysts thanks to a synergistic effect with the small amount of $\mathrm{Cu}$ and selective exposure of $\{111\}$ facets. 


\section{Experimental}

2.1 Chemicals and materials

Hexachloroplatinic(IV) acid hexahydrate $\left(\mathrm{H}_{2} \mathrm{PtCl}_{6} \cdot 6 \mathrm{H}_{2} \mathrm{O} ; 98.5 \%\right)$, copper(II) chloride dihydrate $\left(\mathrm{CuCl}_{2} \cdot 2 \mathrm{H}_{2} \mathrm{O} ; 99.0 \%\right)$, ammonium chloride $\left(\mathrm{NH}_{4} \mathrm{Cl} ; 99.5 \%\right)$, sodium chloride $(\mathrm{NaCl}$; $99.5 \%$ ), sodium tetrahydroborate $\left(\mathrm{NaBH}_{4} ; 95.0 \%\right)$, isopropyl alcohol $(99.7 \%)$, Nafion ${ }^{\circledR}$ dispersion solution (DE521; 5\%), and perchloric acid $\left(\mathrm{HClO}_{4} ; 60 \%\right)$ were purchased from FUJIFILM Wako Pure Chemical. Carbon black (Ketjenblack EC) and Pt/C (TEC10E50E; $46.4 \mathrm{wt} \% \mathrm{Pt}$ ) were purchased from Tanaka Kikinzoku Kogyo. The above chemicals and materials were used as received.

Ammonium hexachloroplatinate(IV) $\left(\left(\mathrm{NH}_{4}\right)_{2} \mathrm{PtCl}_{6}\right)$ was prepared in-house as follows. One gram of $\mathrm{H}_{2} \mathrm{PtCl}_{6} \cdot 6 \mathrm{H}_{2} \mathrm{O}$ was dissolved into $50 \mathrm{~mL}$ of deionized water and the same volume of $3 \mathrm{~mol}$ $\mathrm{L}^{-1}$ of $\mathrm{NH}_{4} \mathrm{Cl}$ aqueous solution was subsequently added. The mixture was kept at $30{ }^{\circ} \mathrm{C}$ for a day, which gave a yellow precipitate. Before experimental use, the purity and yield were confirmed to be acceptable (see Supplementary).

\section{$2.2 \quad$ Synthesis}

$\left(\mathrm{NH}_{4}\right)_{2} \mathrm{PtCl}_{6}(0.013 \mathrm{mmol}), \mathrm{CuCl}_{2}(0.013 \mathrm{mmol})$, and carbon black $(7.5 \mathrm{mg})$ were added to an aqueous solution containing $30 \mathrm{mmol}$ of $\mathrm{NH}_{4} \mathrm{Cl}$ or $\mathrm{NaCl}$. The solution $\mathrm{pH}$ and volume were adjusted to $9.2-9.3$ and $90 \mathrm{~mL}$, respectively. $\mathrm{NaBH}_{4}(30 \mathrm{mg})$ dissolved in $10 \mathrm{~mL}$ of deionized water was injected to start the synthesis reaction. The solution was kept at $30{ }^{\circ} \mathrm{C}$ for $4 \mathrm{~h}$ while stirring. It was subsequently filtered, rinsed, and dried. The samples synthesized with $\mathrm{NH}_{4} \mathrm{Cl}, \mathrm{NaCl}$, or neither were labeled as Amm/C, Sod/C, and None/C, respectively.

\subsection{Characterizations}

The crystal structure was analyzed by powder X-ray diffraction (XRD; Smart-Lab, Rigaku) measurements performed with $\mathrm{Cu} \mathrm{K \alpha}$ radiation. Nano-sized metal precipitates on carbon supports were observed by a transmission electron microscope (TEM; EM-002B, Topcon) or a scanning transmission electron microscope (STEM; HD-2700, Hitachi High-Technologies) operated at $200 \mathrm{kV}$. The elemental composition was measured by an energy dispersive X-ray spectrometer (EDS; TEAM EDS system, AMETEK) equipped on the STEM and induced coupled plasma-atomic emission spectrometer (ICP-AES; Optima 3300XL, Perkin Elmer). Ultraviolet-visible absorption spectra (UVvis; U-3900, Hitachi High-Technologies) were recorded to confirm the complex state of Pt ions in an aqueous solution. The reduction behavior of the metal species was evaluated by ICP-AES measurements against the reaction time.

\subsection{Electrochemical measurements}

All electrochemical measurements were performed in a conventional three-electrode system consisting of a polished glassy carbon electrode (GCE; $0.283 \mathrm{~cm}^{2}$ ), reversible hydrogen electrode (RHE), and platinum coil as the working, reference, and counter electrodes, respectively. Typically, 
catalyst ink was prepared by dispersing $3.7 \mathrm{mg}$ of the catalyst powder in a mixture of ultrapure water (3.8 mL), isopropyl alcohol $(1.2 \mathrm{~mL})$, and Nafion ${ }^{\circledR}$ solution $(14 \mu \mathrm{L})$ followed by ultrasonication. Afterwards, $14.4 \mu \mathrm{L}$ of the catalyst ink was dropped onto the GCE and dried at ambient conditions. Cyclic voltammetry $(\mathrm{CV})$ was conducted in a $\mathrm{N}_{2}$-saturated $\mathrm{HClO}_{4}$ solution $\left(0.1 \mathrm{~mol} \mathrm{~L}^{-1}\right)$ at a scanning rate of $50 \mathrm{mV} \mathrm{s}^{-1}$. The electrochemical active surface area (ECSA) was determined by integrating the electric charge associated with adsorption/desorption of hydrogen atoms in the $\mathrm{CV}$, assuming the charge for monolayer hydrogen adsorption on the Pt surface is $210 \mu \mathrm{C} \mathrm{cm}^{-2}$. Thereafter, the linear sweep voltammogram (LSV) was recorded with a rotating disk electrode (RDE) in $\mathrm{O}_{2}$-saturated $\mathrm{HClO}_{4}$ solution $\left(0.1 \mathrm{~mol} \mathrm{~L}{ }^{-1}\right)$ at a scanning rate of $10 \mathrm{mV} \mathrm{s}^{-1}$. The rotation speed of the working electrode was controlled at 1000, 1250, 1500, 2000, or $2750 \mathrm{rpm}$.

\section{Results and discussion}

\subsection{Synthesis and characterizations}

The catalytic samples were synthesized with $\mathrm{NH}_{4} \mathrm{Cl}(\mathrm{Amm} / \mathrm{C}), \mathrm{NaCl}(\mathrm{Sod} / \mathrm{C})$, or neither (None/C). The crystal structure and composition of bimetallic electrocatalysts significantly affect the ORR catalytic activity $(6,7,21,27-32)$. The synthetic samples in this study should contain $\mathrm{Pt}_{1} \mathrm{Cu}_{1}$ alloy crystals since they were obtained via a chemical reduction of $\mathrm{Pt}$ and $\mathrm{Cu}$ ions at a 1:1 ratio. Figure 1 shows the XRD profiles of the synthetic samples along with the commercial Pt/C. The diffraction peaks of the commercial Pt/C appearing at 39.8, 46.2, 67.5, and $81.3^{\circ}$ are indexed to the (111), (200), (220), and (311) planes of face-centered cubic (fcc) Pt, respectively. All profiles of the synthetic samples exhibit a typical pattern for metallic fcc crystal structures. The diffraction peaks of None/C and Sod/C are located between those of $\mathrm{Pt}$ and $\mathrm{Cu}$, indicating the formation of Pt-Cu alloy crystals. Although $\mathrm{Amm} / \mathrm{C}$ includes $\mathrm{Cu}$ salt in the synthesis solution, the diffraction peaks appear at almost the same position as the commercial Pt/C except for an additional minor peak at $85.7^{\circ}$ of the (222) plane. Therefore, $\mathrm{Cu}$ ions are not reduced completely or redissolved immediately after precipitation during the synthesis of $\mathrm{Amm} / \mathrm{C}$. An explanation of the different $\mathrm{Cu}$ contents is discussed later to reveal the synthesis mechanism.

The composition ratio of $\mathrm{Pt}$ and $\mathrm{Cu}$ in each sample was estimated by Vegard's law, which predicts a linear variation in the lattice constant with the composition, and it was compared to the measurement results by EDS and ICP-AES (Table I). Note that the value obtained by Vegard's law indicates the composition ratio in alloyed crystals, whereas EDS and ICP-AES counterparts reflect the elemental ratio of whole states. Although the lattice constant of Amm/C corresponds to that of pure $\mathrm{Pt}$, a non-negligible amount of $\mathrm{Cu}$ is detected by EDS and ICP-AES, indicating $\mathrm{Cu}$ atoms are doped in the fcc Pt crystals. The EDS and ICP-AES results of None/C and Sod/C suggest that Pt and $\mathrm{Cu}$ are contained at the same ratio, which coincides with the initial additive amount of metal precursors. On the other hand, the content of $\mathrm{Cu}$ atoms in the fcc crystal decreases from the additive ratio in the following order: the additive $(50 \mathrm{at} \%)>\mathrm{Sod} / \mathrm{C}(33 \mathrm{at} \%)>$ None/C $(23 \mathrm{at} \%)$. Therefore, part of $\mathrm{Cu}$ atoms in $\mathrm{Sod} / \mathrm{C}$ and None/C does not exist as alloyed fcc crystals but does exist in other crystal phases, amorphous states, or atomic clusters. 


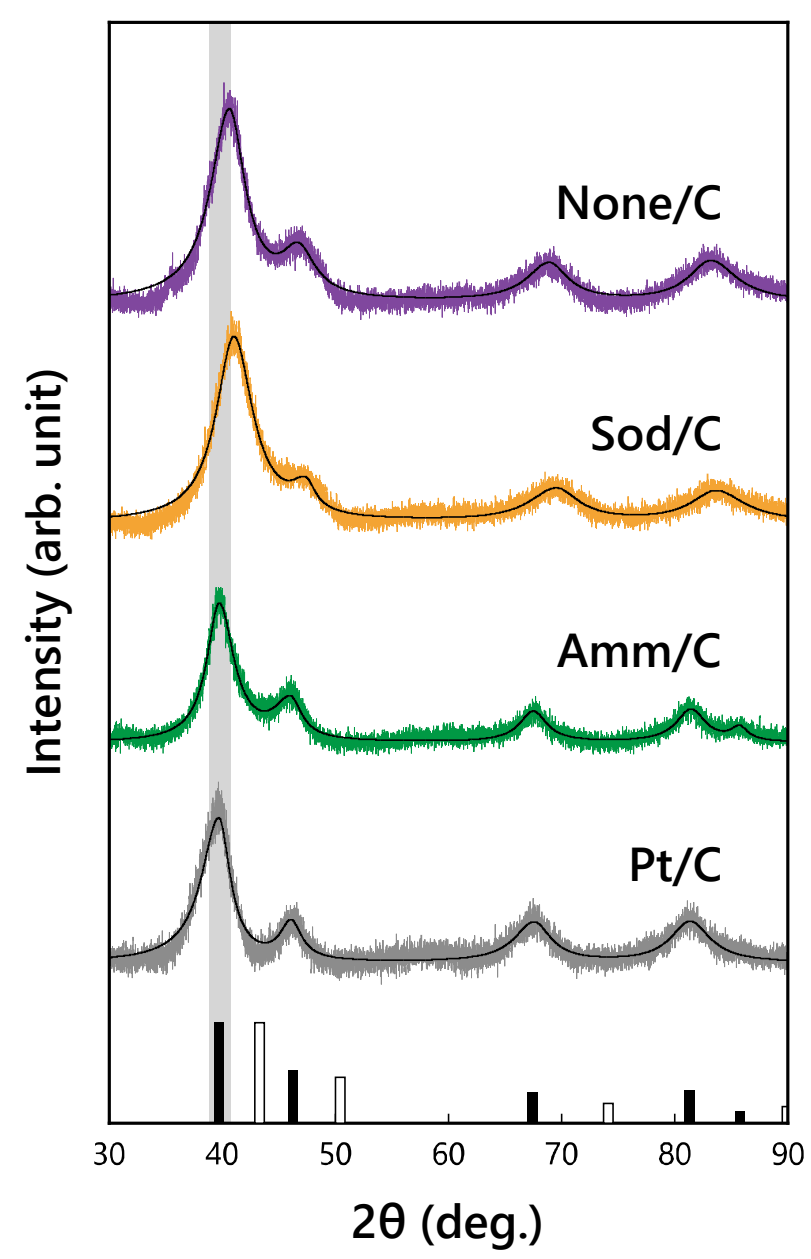

Figure 1 XRD profiles for None/C, Sod/C, Amm/C, and the commercial Pt/C. Black and white bars at the bottom indicate the reference patterns by the International Center for Diffraction Data (ICDD) of fcc Pt (No. 04-0802) and fcc Cu (No. 04-0836), respectively.

Table I Metal compositions of the synthetic samples measured by various methods.

\begin{tabular}{lllllll}
\hline & XRD & & EDS & & ICP & \\
& $\mathrm{Pt}(\mathrm{at} \%)$ & $\mathrm{Cu}(\mathrm{at} \%)$ & $\mathrm{Pt}(\mathrm{at} \%)$ & $\mathrm{Cu}(\mathrm{at} \%)$ & $\mathrm{Pt}(\mathrm{at} \%)$ & $\mathrm{Cu}(\mathrm{at} \%)$ \\
\hline None/C & 77 & 23 & 48 & 52 & 46 & 54 \\
$\mathrm{Sod} / \mathrm{C}$ & 67 & 33 & 49 & 51 & 47 & 53 \\
$\mathrm{Amm} / \mathrm{C}$ & 100 & 0 & 95 & 5 & 94 & 6 \\
\hline
\end{tabular}

TEM observations were performed to reveal the morphological features of the synthetic samples. Nano-sized metal precipitates are uniformly deposited on carbon supports without noticeable aggregation, although carbon black agglomerates in the aqueous solution during the synthesis due to the surfactant-free conditions. Figures $2 \mathrm{a}$ to $2 \mathrm{f}$ show typical images and the corresponding distribution histograms of the particle diameters. None/C contains small nanoparticles, which are $2.4 \mathrm{~nm}$ on average and can be expressed as nanoclusters (Figures 2a and 2d). In contrast, larger particles are synthesized in the presence of $\mathrm{NaCl}$ (Figures $2 \mathrm{~b}$ and 2e) or $\mathrm{NH}_{4} \mathrm{Cl}$ (Figsures $2 \mathrm{c}$ 
and 2f). The mean particle sizes of $\mathrm{Sod} / \mathrm{C}$ and $\mathrm{Amm} / \mathrm{C}$ are 5.0 and $7.6 \mathrm{~nm}$, respectively. The size distribution broadens as the particles grow, which agrees with the general trend.
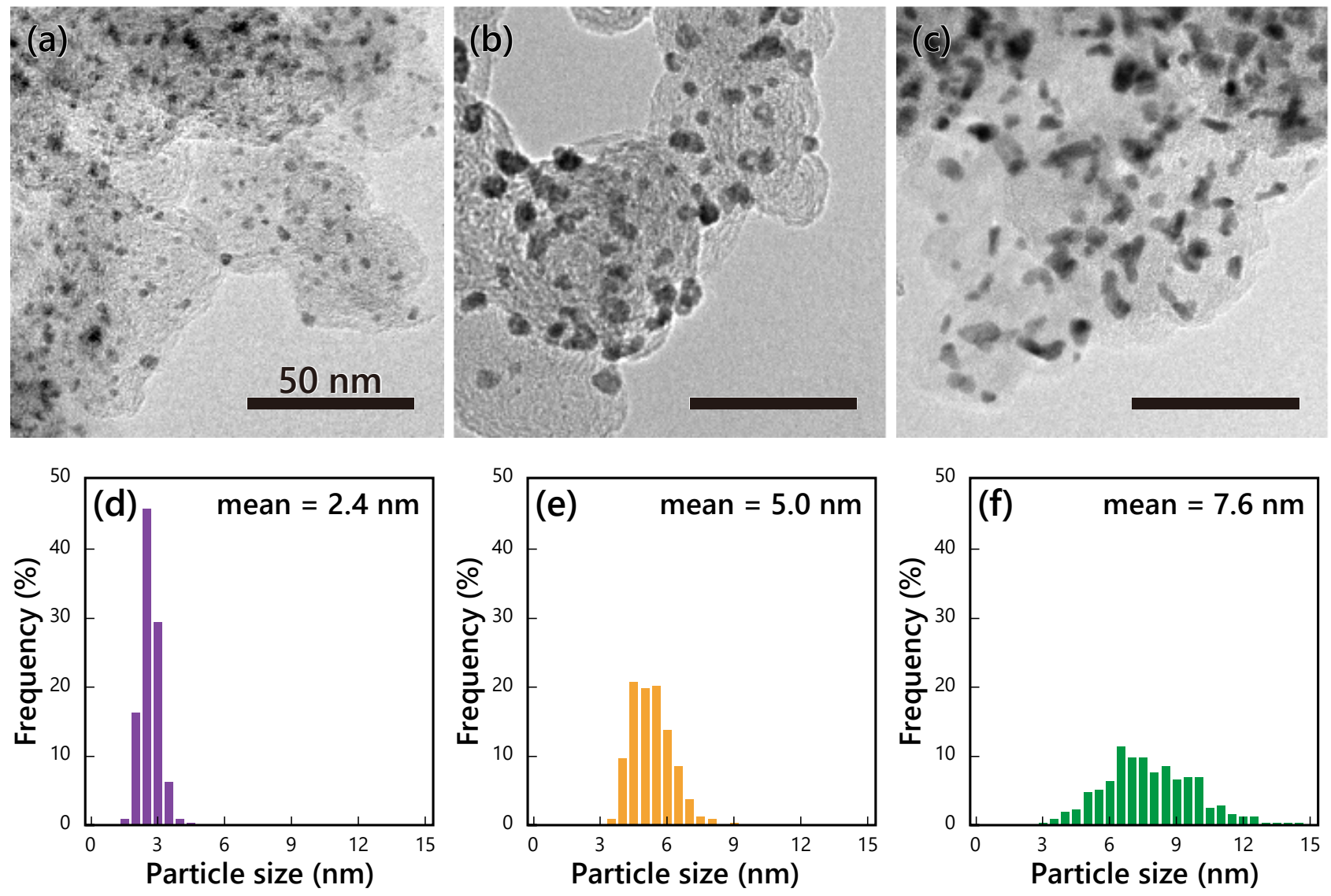

Figure 2 TEM images and particle size distributions of (a)(d) None/C, (b)(e) Sod/C, and (c)(f) $\mathrm{Amm} / \mathrm{C}$.

In addition to particle size, particle shape and/or exposed crystal facets drastically affect the catalytic activities $(21,27-29,32)$. Although the particle sizes differ, both None/C and Sod/C have spherical particle shapes (Figures $2 \mathrm{a}$ and $2 \mathrm{~b}$ ). In contrast, $\mathrm{Amm} / \mathrm{C}$ has triangular, bar-like, and distorted shapes (Figure 2c). STEM experiments were conducted to fully understand the morphological features of Amm/C. Figure 3a shows a high-angle annular dark field (HAADF) image displaying two metallic particles. Figure $3 \mathrm{~b}$ shows a secondary electron (SE) image of the same area. The HAADF and SE images mutually compensate the location of metallic elements and the surface profile. Comparing Figures $3 \mathrm{a}$ and $3 \mathrm{~b}$ reveals the triangular plate-like morphology. The illustration located over Figures $3 \mathrm{a}$ and $3 \mathrm{~b}$ indicates the estimated shape of particles in the STEM images. Consequently, the various shapes in Figure $2 \mathrm{c}$ are nanoplates observed from different directions.

Figure $3 c$ shows a high-resolution TEM (HRTEM) image observed from an edge of the nanoplate. The $0.23-\mathrm{nm}$ spacing of lattice fringes corresponds with the (111) plane of fcc $\mathrm{Pt}$, indicating the top and bottom surfaces of the nanoplates are enclosed by the $\{111\}$ facets. The minor diffraction peak of the (222) plane in Figure 1 also supports the growth orientation. Note that 
thermodynamically favored shape for fcc crystals is cuboctahedron enclosed by $\{100\}$ and $\{110\}$ facets (33), which is nearly spherical such as None/C and Sod/C. This indicates that kinetic control should form the thermodynamically unfavored plate-like morphology. In conclusion of the above characterizations, $\mathrm{Pt}-\mathrm{Cu}$ nanoclusters $(\mathrm{None} / \mathrm{C}), \mathrm{Pt}-\mathrm{Cu}$ nanospheres $(\mathrm{Sod} / \mathrm{C})$, and $\mathrm{Cu}$-doped $\mathrm{Pt}$ nanoplates $(\mathrm{Amm} / \mathrm{C})$ supported on carbon are synthesized.

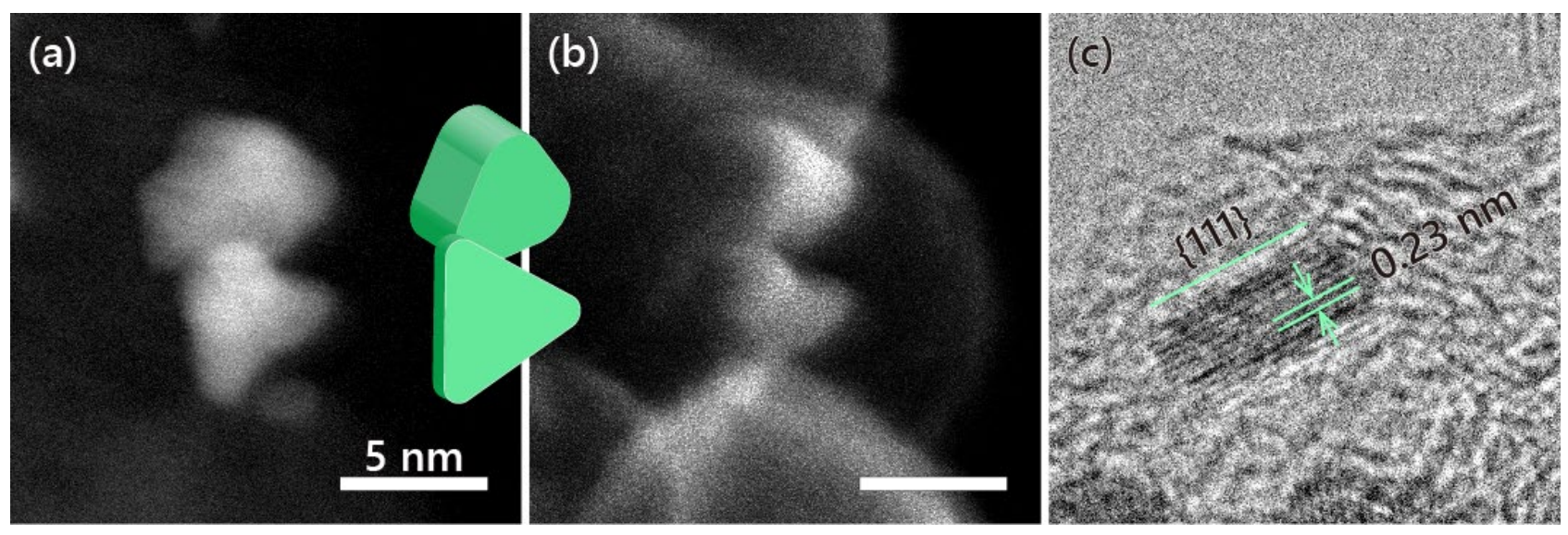

Figure 3 (a) HAADF- and (b) SE-STEM images of the same area and (c) a HRTEM image of Amm/C. Illustration shows triangular nanoplates estimated from (a) and (b).

\subsection{Synthesis mechanism}

Fully understanding the synthesis conditions for each sample is the most important clue to reveal the synthesis mechanism. The complex species of the Pt precursors before the reaction was estimated from the UV-vis spectra (Figure 4a). All solution samples were prepared without carbon black or $\mathrm{Cu}$ salt, and diluted by water to obtain reliable absorbance. The UV-vis spectrum of Sod/C shows a peak around $260 \mathrm{~nm}$, which corresponds to $\left[\mathrm{PtCl}_{6}\right]^{2-}$ in previous reports (34-37). Although $\mathrm{Pt}(\mathrm{IV})$ complex ions tend to hydrolyze in an alkaline solution, an excess concentration of $\mathrm{Cl}^{-}$can prevent it (38), and Sod/C maintains the initial complex structure of $\left[\mathrm{PtCl}_{6}\right]^{2-}$ by adding $\mathrm{NaCl}$.

For None/C, which does not include additive $\mathrm{Cl}^{-}$in the solution, the absorption spectrum broadens toward the shorter wavelength region compared to Sod/C counterpart. The absorption peak of $\left[\mathrm{PtCl}_{6}\right]^{2-}$ at $260 \mathrm{~nm}$ undergoes a blue shift when part of $\mathrm{Cl}^{-}$is exchanged by $\mathrm{OH}^{-}$. For example, the absorption peak appears at $240 \mathrm{~nm}$ for $\left[\mathrm{PtCl}_{4}(\mathrm{OH})_{2}\right]^{2-}$ and $210 \mathrm{~nm}$ for $\left[\mathrm{PtCl}(\mathrm{OH})_{5}\right]^{2-}(34,35)$. Therefore, the peak broadening suggests that $\left[\mathrm{PtCl}_{6-x}(\mathrm{OH})_{x}\right]^{2-}(0 \leq x \leq 6)$ is mixed in the synthesis solution of None/C.

Despite including $\mathrm{NH}_{4} \mathrm{Cl}$, which can supply $\mathrm{Cl}^{-}$to prevent hydrolysis, $\mathrm{Amm} / \mathrm{C}$ does not show absorbance except for that ascribed to the matrix. In other words, neither chloride nor hydroxide complexes are in the solution of Amm/C. Another possible species is $\left[\mathrm{Pt}\left(\mathrm{NH}_{3}\right)_{6}\right]^{4+}(39)$. Although $\mathrm{NH}_{4} \mathrm{Cl}$ may provide $\mathrm{NH}_{4}{ }^{+}$but not $\mathrm{NH}_{3}$, half of the provided $\mathrm{NH}_{4}{ }^{+}$changes into $\mathrm{NH}_{3}$ because the $\mathrm{pH}$ of the synthesis solution corresponds to the acid dissociation constant of $\mathrm{NH}_{4}^{+}(40)$. The amine complex absorbs light at a shorter wavelength than the hydroxide and chloride counterparts according to the spectrochemical series, which predicts the strength order of the ligand field splitting as $\mathrm{NH}_{3}>$ 
$\mathrm{OH}^{-}>\mathrm{Cl}^{-}(41,42)$. Thus, the absorption band of $\left[\mathrm{Pt}\left(\mathrm{NH}_{3}\right)_{6}\right]^{4+}$ should be located at a shorter wavelength region than those of $\left[\mathrm{PtCl}_{6-x}(\mathrm{OH})_{x}\right]^{2-}$ and be hidden in that of the matrix.

(a)

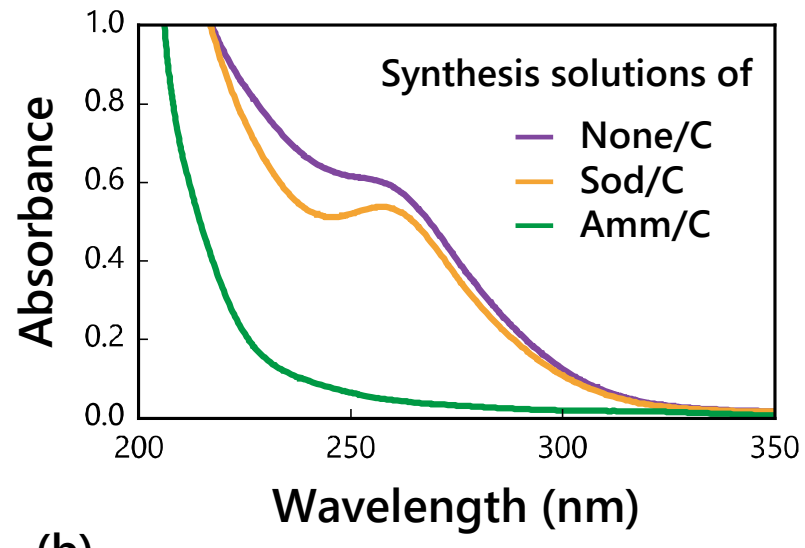

(b)

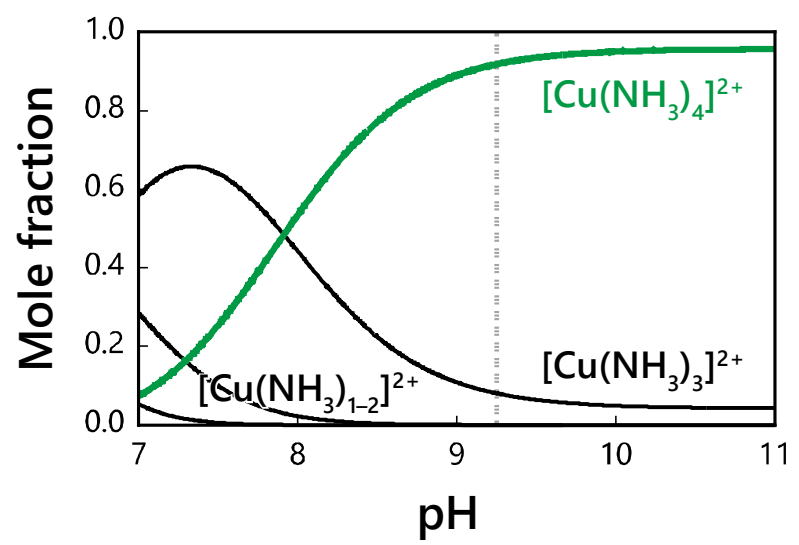

Figure 4 (a) UV-vis spectra of the synthesis solutions and (b) the simulated result of $\mathrm{Cu}$ complex species in the synthesis solution of $\mathrm{Amm} / \mathrm{C}$.

$\mathrm{Cu}$ (II) ions preferentially form amine complexes in the presence of ammonia, whereas hydroxides are stable in the high $\mathrm{pH}$ region without ammonium species. Complex species of $\mathrm{Cu}$ at different $\mathrm{pH}$ values were simulated by solving equations for the equilibrium constants $(40,43,44)$. Figure $4 \mathrm{~b}$ shows the result for $\mathrm{Amm} / \mathrm{C}$, which contains ammonia in the synthesis solution, suggesting that the $\mathrm{Cu}$ complex species around the $\mathrm{pH}$ of the synthesis solution is $\left[\mathrm{Cu}\left(\mathrm{NH}_{3}\right)_{4}\right]^{2+}$ with a small ratio of $\left[\mathrm{Cu}\left(\mathrm{NH}_{3}\right)_{3}\right]^{2+}$, and the $\mathrm{Cu}$ precursor of $\mathrm{Amm} / \mathrm{C}$ is determined to be an amine complex. The other simulations for None/C and Sod/C are shown in Figure S4, suggesting that their $\mathrm{Cu}$ precursors are both $\mathrm{Cu}$ hydroxide as expected. In regard to the synthesis conditions, it should also be noted that $\mathrm{Cl}^{-}$ contained in the solution of $\mathrm{Sod} / \mathrm{C}$ and $\mathrm{Amm} / \mathrm{C}$ can behave as an oxidative etchant when $\mathrm{O}_{2}$ is present in the reaction field (45), which is often denoted as $\mathrm{Cl}^{-} / \mathrm{O}_{2}$.

To evaluate the kinetic features for each synthesis condition, the concentrations of metal species in the synthesis solutions were tracked by ICP-AES measurements with various reaction times. Figure 5 plots the metal ion concentrations as a function of reaction time normalized by the initial 
value. When focusing on the early stage of Pt reduction (i.e., the first 30 minutes) in Figure 5a, the reduction rates clearly differ. Reduction of $\mathrm{Pt}$ ions during the synthesis of None/C is relatively fast and is completed within 5 minutes, while Sod/C takes 30 minutes. Moreover, comparing Sod/C and $\mathrm{Amm} / \mathrm{C}$, although the gradients of the section between 1-30 minutes are almost the same, the reduction rate is smaller for $\mathrm{Amm} / \mathrm{C}$ than $\mathrm{Sod} / \mathrm{C}$ because they reach different values. Hence, the reduction rate of $\mathrm{Pt}$ decreases in the following order: None/C $>>\mathrm{Sod} / \mathrm{C}>\mathrm{Amm} / \mathrm{C}$. In the chemical reduction synthesis of nanoparticles, a reduction leads to smaller particle sizes, which may be responsible for the smaller nanoparticles of None/C.

The variations in the reduction rates among the present synthesis conditions should be a consequence of the difference in the complex species of precursors (46) and/or oxidative etching by $\mathrm{Cl}^{-} / \mathrm{O}_{2}(45,47-49)$. The reduction rate for None/C without $\mathrm{Cl}^{-}$is much faster than those for Sod/C and $\mathrm{Amm} / \mathrm{C}$ with $\mathrm{Cl}^{-}$. This suggests that $\mathrm{Cl}^{-} / \mathrm{O}_{2}$ plays a key role in delaying the reaction of $\mathrm{Pt}$ reduction (18). It should be noted that the reducing power during the synthesis of $\mathrm{Amm} / \mathrm{C}$ expires before the completion of precipitation reaction, and $\mathrm{Pt}$ ions remain in the solution even after stirring for $4 \mathrm{~h}$.

\section{(a)}

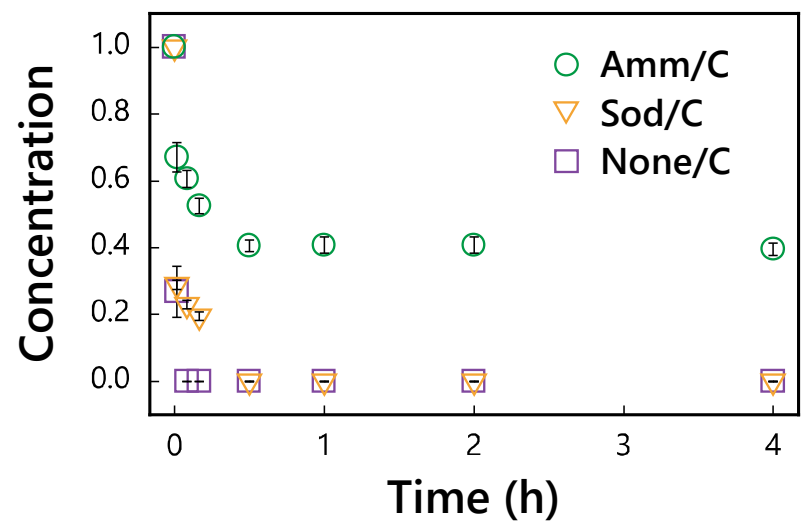

(b)

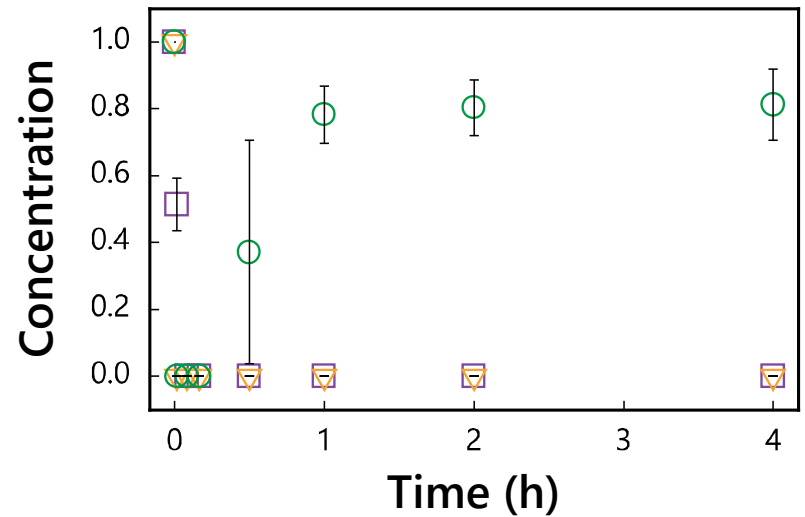

$\begin{array}{ll}\text { Figure } 5 & \text { (a) } \mathrm{Pt} \text { and (b) } \mathrm{Cu} \text { concentrations in the synthesis solutions as a function of reaction }\end{array}$ time. Error bars indicate standard deviations $(\mathrm{N}=3)$. 
Figure $5 \mathrm{~b}$ shows precipitation behavior of $\mathrm{Cu}$ in the synthesis solutions. The most noticeable feature is that $\mathrm{Cu}$ ions are immediately reduced and subsequently redissolved during the synthesis of $\mathrm{Amm} / \mathrm{C}$, which is the reason for the low $\mathrm{Cu}$ loading in $\mathrm{Amm} / \mathrm{C}$. Therefore, the $\mathrm{Cu}$-amine complex ion simulated as the main species in Figure $4 \mathrm{~b}$ is extremely stable under the present conditions and is formed preferentially when the reducing power is expired. Despite the result that reduction rate of $\mathrm{Pt}$ for $\mathrm{Amm} / \mathrm{C}$ is the slowest, its $\mathrm{Cu}$ counterpart at the early stage is comparable or slightly faster. The standard electrode potential of the $\mathrm{Cu}$ complex ions into metallic $\mathrm{Cu}$ is $-0.054 \mathrm{~V}$ vs. normal hydrogen electrode (NHE) for $\left[\mathrm{Cu}\left(\mathrm{NH}_{3}\right)_{4}\right]^{2+}$ and $-0.222 \mathrm{~V}$ vs. NHE for $\mathrm{Cu}(\mathrm{OH})_{2}(50,51)$. Note that the potential for $\left[\mathrm{Cu}\left(\mathrm{NH}_{3}\right)_{4}\right]^{2+}$ is derived from the standard Gibbs energies of formation. The $\mathrm{Cu}$-amine complex ion, namely, the $\mathrm{Cu}$ precursor for $\mathrm{Amm} / \mathrm{C}$ is reduced easier and faster although the precipitated metal $\mathrm{Cu}$ starts to redissolve simultaneously with the expiration of the reducing power.

The synthesis of metal nanoparticles with anisotropic morphologies, including nanoplates like Amm/C, generally requires capping agents with long chains to select the growth direction and/or seeds of a second metal to introduce defects in their crystals at the nucleation step. Because molecules containing $\mathrm{N}$ atoms strongly adsorb on a Pt surface, they are often chosen as capping agents (22), however, ammonia or ammonium ions are too small to exhibit a capping effect. Besides, in some cases, a trace amount of second metal ions behaves as seeds and assists in forming anisotropic $\mathrm{Pt}$ nanoparticles $(52,53)$.

To reveal the synthesis mechanism and to reach the origin of the morphological features, further experiments were conducted. Two additional conditions based on the procedure to synthesize $\mathrm{Amm} / \mathrm{C}$ were undertaken. One was without a $\mathrm{Cu}$ salt in solution, and the other was while purging by $\mathrm{N}_{2}$ gas to expel dissolved $\mathrm{O}_{2}$. Figure 6 shows the typical TEM images of them. As shown in Figure 6a, Amm/C synthesized without $\mathrm{Cu}$ salt exhibits non-spherical nanoparticles similar to that synthesized with $\mathrm{Cu}$ salt in Figure 2c. The nanoplates synthesized without $\mathrm{Cu}$ clearly suggest that the formation of the plate-like morphology is not assisted by $\mathrm{Cu}$ seeds in the present study. On the other hand, purging with $\mathrm{N}_{2}$ during the synthesis forms spherical nanoparticles without plate-like nanoparticles (Figure 6b), indicating that dissolved $\mathrm{O}_{2}$ in the solution with the ammonium species plays a key role in forming the plate-like morphology.

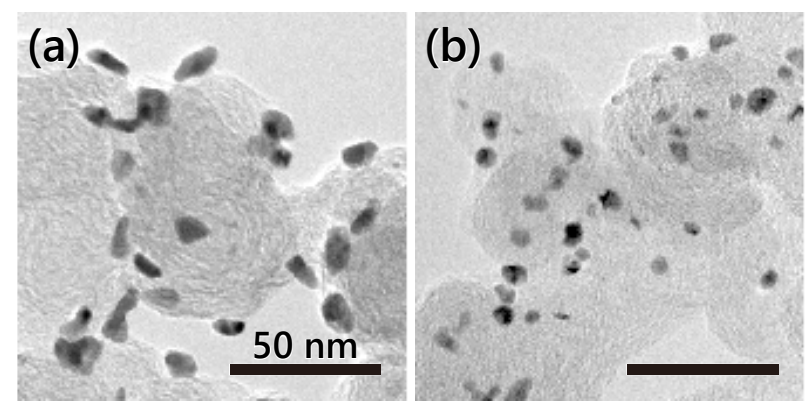

Figure 6 TEM images of Amm/C synthesized (a) without $\mathrm{Cu}$ salt and (b) under a $\mathrm{N}_{2}$ atmosphere. 
When $\mathrm{Pt}$ ions are reduced in the presence of $\mathrm{Cl}^{-} / \mathrm{O}_{2}$, $\mathrm{Pt}$ nanoparticles gradually grow while oscillating between precipitation and dissolution. Then capping agents restrict the precipitation or dissolution sites, resulting in selective growth $(22,23)$. Selective adsorption of capping agents is an important factor for anisotropic growth of nanoparticles. For ammonia molecules and ammonium ions in the synthesis solution of Amm/C, adsorption on the (111) facet of Pt is weaker than other facets $(54,55)$. Although ammonium species have no long chain to express the capping effect, an explanation for synthesis mechanism of nanoplates can be deduced by focusing on the electrical charges of the precursor and surface. During the synthesis of Amm/C, etched Pt ions are stabilized into negatively charged $\left[\mathrm{PtCl}_{6}\right]^{2-}$ by coordinating with $\mathrm{Cl}^{-}(23,45)$, while the Pt precursor of Amm/C is positively charged $\left[\mathrm{Pt}\left(\mathrm{NH}_{3}\right)_{6}\right]^{4+}$. Since negatively charged $\left[\mathrm{PtCl}_{6}\right]^{2-}$ prefers to precipitate on positively charged facets covered by $\mathrm{NH}_{4}{ }^{+},<111>$ growth is inhibited and a plate-like morphology, which exposes the $\{111\}$ facets, is formed.

\subsection{Electrochemical measurements}

For Pt-Cu bimetallic electrocatalysts, it has been reported that exposed $\mathrm{Cu}$ atoms dissolve during pretreatment in an acidic atmosphere and a Pt thin layer forms on the surface $(13,56)$. To stabilize the electrode and obtain reproducible data, the electrochemical properties were evaluated after applying potential for 200 cycles. ECSA, which was determined from the CV in Figure S5, is 35.5, 19.7, and $21.0 \mathrm{~m}^{2} \mathrm{~g}^{-1}$ for None/C, Sod/C, and Amm/C, respectively. Since ECSA highly depends on the specific surface area of the catalytic particles, None/C, which carries the tiny nanoclusters on the surface, shows comparable value to the commercial $\mathrm{Pt} / \mathrm{C}\left(36.4 \mathrm{~m}^{2} \mathrm{~g}^{-1}\right)$, whereas those of Sod/C and $\mathrm{Amm} / \mathrm{C}$ are smaller. It is difficult to unconditionally predict ECSAs of Sod/C and Amm/C from their particle sizes due to their differences in shape. However, considering the size of plate-like materials is often overestimated against the spherical counterpart, the result that $\mathrm{Amm} / \mathrm{C}$ with larger plate-like particles shows a slightly larger ECSA than Sod/C with smaller spherical particles is reasonable.

The ORR catalytic performance was investigated on RDE at various rotation speeds. The polarization curve was corrected for the non-Faradaic background current by subtracting the current in $\mathrm{CV}$ recorded in $\mathrm{N}_{2}$-saturated electrolyte. The kinetic current for the ORR was derived from the segment of the Koutecky-Levich plot, and normalized by the Pt loading or ECSA. Figures 7a and 7b present the half-cell potentials as a function of mass activity and specific activity, respectively. The gradients coincide with that of Tafel slope due to the linear normalization. For all curves in Figures $7 \mathrm{a}$ and $7 \mathrm{~b}$, the slope gradually changes from -60 to $-120 \mathrm{mV}$ decade ${ }^{-1}$ as the current density increases, indicating the same ORR mechanism for all of the synthetic samples and the commercial Pt/C (57, 58). It should be noted that the rate-limiting step in the ORR for Pt-based catalysts is electron transferring to adsorbed $\mathrm{O}_{2}$ regardless of the current density region. Consequently, the change in Tafel slope does not imply a change in the rate-limiting step but is related to the onset potential of adsorption of oxygenated species $(11-15,57,58)$. 
(a)

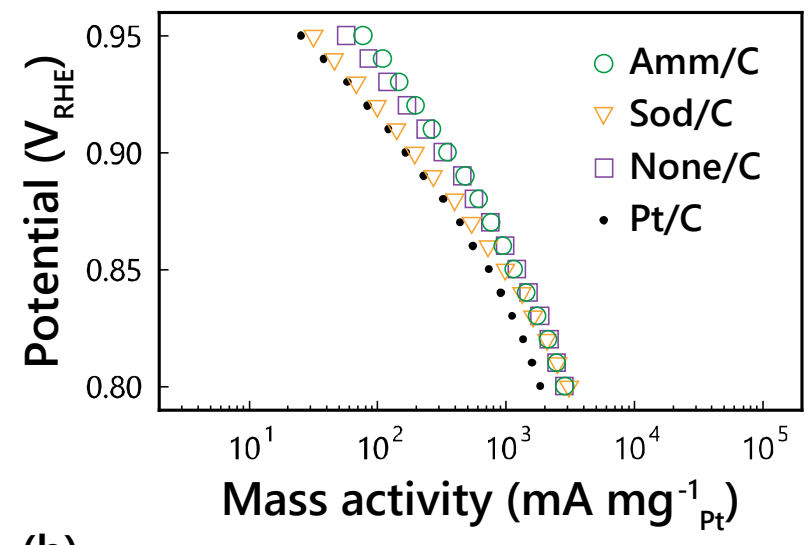

(b)

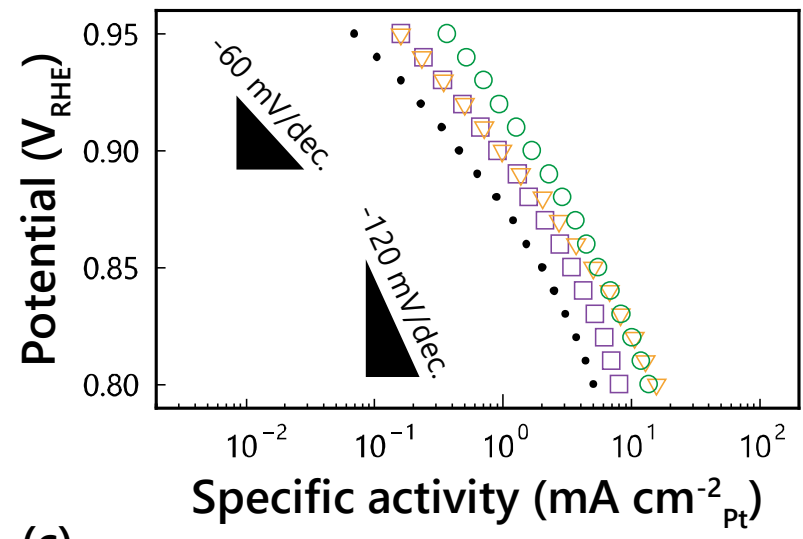

(c)

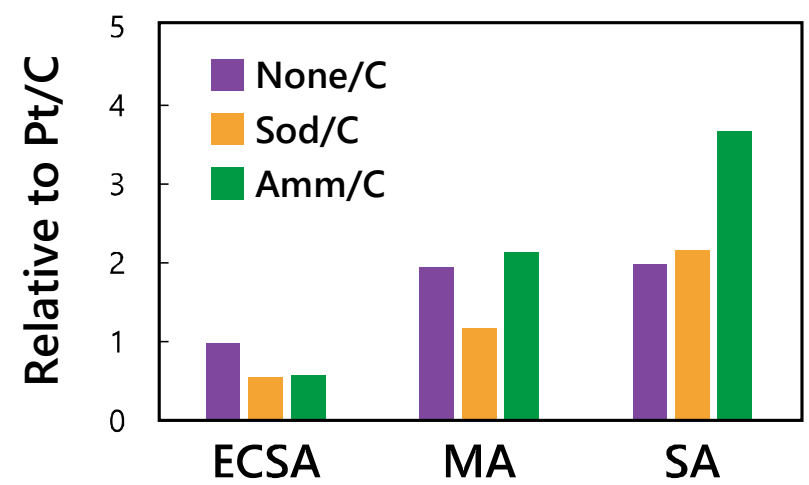

Figure $7 \quad$ Half-cell potentials as a function of (a) mass activity (MA) and (b) specific activity (SA). (c) The ORR catalytic properties at $0.9 \mathrm{~V}$ vs. RHE normalized by those of the commercial Pt/C. 
Table II The ORR catalytic properties at $0.9 \mathrm{~V}$ vs. RHE and relative values against the commercial Pt/C.

\begin{tabular}{lllllll}
\hline & ECSA & \multicolumn{3}{c}{ Mass activity } & \multicolumn{3}{c}{ Specific activity } \\
& $\left(\mathrm{m}^{2} \mathrm{~g}^{-1} \mathrm{Pt}\right)$ & vs. Pt/C & $\left(\mathrm{mA} \mathrm{mg}^{-1} \mathrm{Pt}\right)$ & vs. Pt/C & $\left(\mathrm{mA} \mathrm{cm}^{-2} \mathrm{Pt}\right)$ & vs. Pt/C \\
\hline $\mathrm{Pt} / \mathrm{C}$ & 36.4 & 1 & 166 & 1 & 0.46 & 1 \\
$\mathrm{None} / \mathrm{C}$ & 35.5 & 0.98 & 323 & 1.95 & 0.91 & 1.98 \\
$\mathrm{Sod} / \mathrm{C}$ & 19.7 & 0.54 & 194 & 1.17 & 0.99 & 2.15 \\
$\mathrm{Amm} / \mathrm{C}$ & 21.0 & 0.58 & 354 & 2.13 & 1.69 & 3.67 \\
\hline
\end{tabular}

Table II summarizes the mass and specific activities at $0.9 \mathrm{~V}$ vs. RHE along with ECSA, and Figure $7 \mathrm{c}$ exhibits the relative ORR catalytic properties against the commercial $\mathrm{Pt} / \mathrm{C}$. The mass activities for None/C, Sod/C, and Amm/C are 323, 194 and $354 \mathrm{~mA} \mathrm{mg}{ }^{-1}$, respectively. Amm/C is 2.13-times greater than that for the commercial $\mathrm{Pt} / \mathrm{C}$. While mass activity is the most important factor based on the perspective of industry and commerce $(1,59)$, it is determined by the product of ECSA and specific activity, thus itself is basically uncontrollable.

Compared to the specific activity of the commercial $\mathrm{Pt} / \mathrm{C}\left(0.46 \mathrm{~mA} \mathrm{~cm}^{-2}\right)$, those for None/C and Sod/C, which have spherical nanoparticles with different sizes, are twice as high. The enhanced activity is explained by the synergistic effect between $\mathrm{Pt}$ and $\mathrm{Cu}$. It has been theoretically and experimentally demonstrated that alloying of Pt atoms with a transition metal changes the surface electronic structure, modifies the bonding energy with oxygenated species, and leads to the high activity (12-14). Particle size and/or distance (20, 28, 60-62), and the atomic composition ratio in the alloy crystal (5-7, 10, 30-32) might also affect the activity. However, their impact is not significant in the present system or the comprehensive value results in the same level. Although further experiments are required for a full understanding, the difference in mass activity between None/C and Sod/C is dominantly ascribed to the difference in ECSA.

$\mathrm{Amm} / \mathrm{C}$ exhibits the highest specific activity $\left(1.69 \mathrm{~mA} \mathrm{~cm}^{-2}\right)$ in this study, and is superior to the commercial $\mathrm{Pt} / \mathrm{C}$ by 3.67 times. As discussed above, the catalytic particles in $\mathrm{Amm} / \mathrm{C}$ are $\mathrm{Cu}-$ doped Pt nanoplates selectively exposing the $\{111\}$ facets. According to previous studies on a model electrode for the ORR in aqueous perchloric acid solution, the Pt (111) facet is more active than the polycrystalline Pt surface. However, neither is remarkable nor the best even among low index facets $(21,27-29,32)$. Therefore, the perspective of the exposed crystal facet is insufficient to interpret the high activity. The small amount of doped $\mathrm{Cu}$ atoms no doubt plays an important role for the ORR. Compared to the pure Pt crystal and alloy, a different trend of the ORR performance against crystal facet has been reported $(29,32)$. Stamenkovic and his co-workers have suggested that an alloyed Pt (111) facet shows a much higher activity than other low index facets by using well-defined electrode of $\mathrm{Pt}_{3} \mathrm{Ni}$ with Pt skin, while Pt (111) is less active than Pt (110) in the pure crystal system (29). The enhanced specific activity of Amm/C arises from both the selective exposure of (111) facet and the existence of $\mathrm{Cu}$ atoms in $\mathrm{Pt}$ crystal.

Although some reports have focused on the relationship between the metal compositions of 
electrocatalyst and the ORR properties, controlling the range of the second metal loading is limited to form intermetallic alloy with Pt $(5-7,10,30-32)$. It is noteworthy that composition ratio of the second metal in catalytic particles is generally higher than 20 at $\%$, whereas the $\mathrm{Cu}$ ratio for Amm/C is less than 10 at $\%$ as written in Table I. The improved specific activity of Amm/C suggests that the small amount of doped $\mathrm{Cu}$ atoms can induce a synergistic effect with the Pt surface to enhance the ORR performance on (111) facet. These results provide motivation to investigate the lower region of the second metal loadings in Pt-based electrocatalysts.

\section{Conclusions}

Carbon-supported Pt-Cu nanoclusters (None/C), Pt-Cu nanospheres (Sod/C), and $\mathrm{Cu}$-doped Pt nanoplates $(\mathrm{Amm} / \mathrm{C})$ were successfully synthesized by a simple one-step method without a polymer surfactant. During the synthesis of Sod/C and $\mathrm{Amm} / \mathrm{C}, \mathrm{Cl}^{-}$ions with dissolved $\mathrm{O}_{2}$ work as an oxidative etchant $\left(\mathrm{Cl}^{-} / \mathrm{O}_{2}\right)$ to delay the reduction rate, resulting in larger particles. $\mathrm{Cl}^{-} / \mathrm{O}_{2}$ and $\mathrm{NH}_{4}{ }^{+}$ are triggers to form the plate-like morphology of $\mathrm{Amm} / \mathrm{C}$. The $\mathrm{Cu}$-doped Pt nanoplates exhibit a 3.67times higher ORR catalytic activity than the commercial Pt catalysts due to a synergistic effect with a small amount of $\mathrm{Cu}$ and selective exposure of the $\{111\}$ facets. The result suggests that a large amount of $\mathrm{Cu}$ to form intermetallic alloys is unnecessary for the enhanced ORR performance.

In addition, $\left(\mathrm{NH}_{4}\right)_{2} \mathrm{PtCl}_{6}$ which was used as the $\mathrm{Pt}$ salt, is the known intermediate product in the recycling process of $\mathrm{Pt}(63,64)$. Therefore, the present study shows a possibility to combine the material synthesis and resource recovery into one process. However, the Pt yield in the synthesis of $\mathrm{Amm} / \mathrm{C}$ is insufficient for practical use due to the expiration of reducing power. Other reducing agents with a continuous effect will enhance the Pt yield. Moreover, the ORR catalytic performance should be further enhanced because a wider plate will be obtained.

\section{Acknowledgement}

This work was partially supported by JSPS KAKENHI Grant Number JP18H03416.

\section{References}

1. M. Debe, Electrocatalyst approaches and challenges for automotive fuel cells. Nature 486, 43-51 (2012).

2. Fuel Cell Technologies Office Multi-Year Research, Developement, and Demonstration Plan (2017).

3. T. Toda, H. Igarashi, H. Uchida, M. Watanabe, Enhancement of the electroreduction of oxygen on Pt alloys with Fe, Ni, and Co. Journal of the Electrochemical Society 146, 3750-3756 (1999).

4. R. Srivastava, P. Mani, N. Hahn, P. Strasser, Efficient oxygen reduction fuel cell electrocatalysis on voltammetrically dealloyed Pt-Cu-Co nanoparticles. Angewandte Chemie-International Edition 46, 8988-8991 (2007).

5. P. Mani, R. Srivastava, P. Strasser, Dealloyed Pt-Cu core-shell nanoparticle electrocatalysts for use in PEM fuel cell cathodes. Journal of Physical Chemistry C 112, 2770-2778 (2008).

6. M. Oezaslan, F. Hasche, P. Strasser, Oxygen Electroreduction on PtCo3, PtCo and Pt3Co Alloy Nanoparticles for Alkaline and Acidic PEM Fuel Cells. Journal of the Electrochemical Society 159, B394-B405 (2012). 
7. Y. Sohn, J. Park, P. Kim, J. Joo, Dealloyed PtCu catalyst as an efficient electrocatalyst in oxygen reduction reaction. Current Applied Physics 15, 993-999 (2015).

8. V. Pryadchenko et al., Bimetallic $\mathrm{PtCu}$ core-shell nanoparticles in $\mathrm{PtCu} / \mathrm{C}$ electrocatalysts: Structural and electrochemical characterization. Applied Catalysis a-General 525, 226-236 (2016).

9. J. Choi et al., Gram-scale synthesis of highly active and durable octahedral PtNi nanoparticle catalysts for proton exchange membrane fuel cell. Applied Catalysis B-Environmental 225, 530-537 (2018).

10. Y. Liu et al., Preparation and application in assembling high-performance fuel cell catalysts of colloidal PtCu alloy nanoclusters. Journal of Power Sources 395, 66-76 (2018).

11. J. Kitchin, J. Norskov, M. Barteau, J. Chen, Modification of the surface electronic and chemical properties of $\operatorname{Pt}(111)$ by subsurface $3 d$ transition metals. Journal of Chemical Physics 120, 10240-10246 (2004).

12. V. Stamenkovic et al., Changing the activity of electrocatalysts for oxygen reduction by tuning the surface electronic structure. Angewandte Chemie-International Edition 45, 2897-2901 (2006).

13. V. Stamenkovic et al., Trends in electrocatalysis on extended and nanoscale Pt-bimetallic alloy surfaces. Nature Materials 6, 241-247 (2007).

14. H. Hansen, V. Viswanathan, J. Norskov, Unifying Kinetic and Thermodynamic Analysis of 2 e(-) and 4 e(-) Reduction of Oxygen on Metal Surfaces. Journal of Physical Chemistry C 118, 6706-6718 (2014).

15. A. Nilekar, M. Mavrikakis, Improved oxygen reduction reactivity of platinum monolayers on transition metal surfaces. Surface Science 602, L89-L94 (2008).

16. J. Zhang, H. Yang, J. Fang, S. Zou, Synthesis and Oxygen Reduction Activity of Shape-Controlled Pt3Ni Nanopolyhedra. Nano Letters 10, 638-644 (2010).

17. B. Larsen et al., Platinum Nanoplates as Fuel Cell Electrocatalysts. Journal of the Electrochemical Society $\mathbf{1 5 9 ,}$ F622-F627 (2012).

18. L. Ma et al., Control Over the Branched Structures of Platinum Nanocrystals for Electrocatalytic Applications. Acs Nano 6, 9797-9806 (2012).

19. H. Liu et al., Synthesis of ultrathin platinum nanoplates for enhanced oxygen reduction activity. Chemical Science 9, 398-404 (2018).

20. K. KINOSHITA, PARTICLE-SIZE EFFECTS FOR OXYGEN REDUCTION ON HIGHLY DISPERSED PLATINUM IN ACID ELECTROLYTES. Journal of the Electrochemical Society 137, 845-848 (1990).

21. A. Bandarenka, H. Hansen, J. Rossmeisl, I. Stephens, Elucidating the activity of stepped Pt single crystals for oxygen reduction. Physical Chemistry Chemical Physics 16, 13625-13629 (2014).

22. Z. Peng, H. Yang, Designer platinum nanoparticles: Control of shape, composition in alloy, nanostructure and electrocatalytic property. Nano Today 4, 143-164 (2009).

23. R. Long, S. Zhou, B. Wiley, Y. Xiong, Oxidative etching for controlled synthesis of metal nanocrystals: atomic addition and subtraction. Chemical Society Reviews 43, 6288-6310 (2014).

24. D. Li et al., Surfactant Removal for Colloidal Nanoparticles from Solution Synthesis: The Effect on Catalytic Performance. Acs Catalysis 2, 1358-1362 (2012).

25. E. Antolini, Carbon supports for low-temperature fuel cell catalysts. Applied Catalysis B-Environmental 88, 124 (2009).

26. Y. Wang, B. Fang, H. Li, X. Bi, H. Wang, Progress in modified carbon support materials for Pt and Pt-alloy 
cathode catalysts in polymer electrolyte membrane fuel cells. Progress in Materials Science 82, 445-498 (2016).

27. N. MARKOVIC, H. GASTEIGER, P. ROSS, OXYGEN REDUCTION ON PLATINUM LOW-INDEX SINGLE-CRYSTAL SURFACES IN SULFURIC-ACID-SOLUTION - ROTATING RING-PT(HKL) DISK STUDIES. Journal of Physical Chemistry 99, 3411-3415 (1995).

28. N. Markovic, H. Gasteiger, P. Ross, Kinetics of oxygen reduction on Pt(hkl) electrodes: Implications for the crystallite size effect with supported Pt electrocatalysts. Journal of the Electrochemical Society 144, 1591-1597 (1997).

29. V. R. Stamenkovic et al., Improved Oxygen Reduction Activity on $\mathrm{Pt}<\mathrm{sub}>3</ \mathrm{sub}>\mathrm{Ni}(111)$ via Increased Surface Site Availability. Science 315, 493-497 (2007).

30. C. Wang et al., Correlation Between Surface Chemistry and Electrocatalytic Properties of Monodisperse PtxNi1x Nanoparticles. Advanced Functional Materials 21, 147-152 (2011).

31. Y. Liu, C. Hangarter, U. Bertocci, T. Moffat, Oxygen Reduction Reaction on Electrodeposited Pt100-xNix: Influence of Alloy Composition and Dealloying. Journal of Physical Chemistry C 116, 7848-7862 (2012).

32. S. Kobayashi, M. Wakisaka, D. Tryk, A. Iiyama, H. Uchida, Effect of Alloy Composition and Crystal Face of Pt-Skin/Pt100-xCox [(111), (100), and (110)] Single Crystal Electrodes on the Oxygen Reduction Reaction Activity. Journal of Physical Chemistry C 121, 11234-11240 (2017).

33. Y. Xia, Y. Xiong, B. Lim, S. Skrabalak, Shape-Controlled Synthesis of Metal Nanocrystals: Simple Chemistry Meets Complex Physics? Angewandte Chemie-International Edition 48, 60-103 (2009).

34. T. Mang, B. Breitscheidel, P. Polanek, H. Knözinger, Adsorption of platinum complexes on silica and alumina: Preparation of non-uniform metal distributions within support pellets. Applied Catalysis A: General 106, 239 258 (1993).

35. Z. Jin, Z. Chen, Q. Li, C. Xi, X. Zheng, On the conditions and mechanism of PtO2 formation in the photoinduced conversion of H2PtCl6. Journal of Photochemistry and Photobiology A: Chemistry 81, 177 - 182 (1994).

36. M. Georgieva, B. Andonovski, Determination of platinum(IV) by UV spectrophotometry. Analytical and Bioanalytical Chemistry 375, 836-839 (2003).

37. Z. Tang, D. Geng, G. Lu, A simple solution-phase reduction method for the synthesis of shape-controlled platinum nanoparticles. Materials Letters 59, 1567-1570 (2005).

38. W. A. Spieker, J. Liu, J. T. Miller, A. J. Kropf, J. R. Regalbuto, An EXAFS study of the co-ordination chemistry of hydrogen hexachloroplatinate(IV). Applied Catalysis A: General 232, 219-235 (2002).

39. B. Farrell, I. Sevonkaev, D. Goia, Preparation of Dispersed Spherical Platinum Particles with Controlled Size and Internal Structure Versatile and cost-effective route to platinum powders for large scale electronic applications. Platinum Metals Review 57, 161-168 (2013).

40. R. Goldberg, N. Kishore, R. Lennen, Thermodynamic quantities for the ionization reactions of buffers. Journal of Physical and Chemical Reference Data 31, 231-370 (2002).

41. R. Tsuchida, Absorption Spectra of Co-ordination Compounds. I. Bulletin of the Chemical Society of Japan 13, $388-400(1938)$

42. T. Ishii, S. Tsuboi, G. Sakane, M. Yamashita, B. K. Y. Breedlove, - Universal spectrochemical series of sixcoordinate octahedral metal complexes for modifying the ligand field splitting. - Dalton Transactions, - 680 (2009). 
43. L. Trevani, J. Roberts, P. Tremaine, Copper(II)-ammonia complexation equilibria in aqueous solutions at temperatures from 30 to 250 degrees C by visible spectroscopy. Journal of Solution Chemistry 30, 585-622 (2001).

44. K. Powell et al., Chemical speciation of environmentally significant metals with inorganic ligands - Part 2: The $\mathrm{Cu} 2+-\mathrm{OH}-, \mathrm{Cl}-, \mathrm{CO} 32-, \mathrm{SO} 42-$, and PO43- systems - (IUPAC technical report). Pure and Applied Chemistry 79, 895-950 (2007).

45. B. Wiley, T. Herricks, Y. Sun, Y. Xia, Polyol synthesis of silver nanoparticles: Use of chloride and oxygen to promote the formation of single-crystal, truncated cubes and tetrahedrons. Nano Letters 4, 1733-1739 (2004).

46. T. Yang, K. Gilroy, Y. Xia, Reduction rate as a quantitative knob for achieving deterministic synthesis of colloidal metal nanocrystals. Chemical Science 8, 6730-6749 (2017).

47. Y. Xiong et al., Kinetically controlled synthesis of triangular and hexagonal nanoplates of palladium and their SPR/SERS properties. Journal of the American Chemical Society 127, 17118-17127 (2005).

48. Y. Wang, H. Peng, J. Liu, C. Huang, Y. Xia, Use of Reduction Rate as a Quantitative Knob for Controlling the Twin Structure and Shape of Palladium Nanocrystals. Nano Letters 15, 1445-1450 (2015).

49. N. Nalajala, A. Chakraborty, B. Bera, M. Neergat, Chloride (Cl-) ion-mediated shape control of palladium nanoparticles. Nanotechnology 27, (2016).

50. G. Milazzo, S. Caroli, V. K. Sharma, C. International Union of Pure and Applied Chemistry. Electrochemistry, Tables of standard electrode potentials. (New York \%8 c1978, Wiley, 1978).

51. A. J. Bard, R. Parsons, J. Jordan, C. International Union of Pure and Applied, Standard potentials in aqueous solution. (New York \%8 1985, M. Dekker, 1985).

52. X. Teng, H. Yang, Synthesis of platinum multipods: An induced anisotropic growth. Nano Letters 5, 885-891 (2005).

53. S. Lim et al., Synthesis of Platinum Cubes, Polypods, Cuboctahedrons, and Raspberries Assisted by Cobalt Nanocrystals. Nano Letters 10, 964-973 (2010).

54. J. M. Gohndrone et al., Ammonia adsorption and decomposition on several faces of platinum. Journal of Vacuum Science \& Technology A 7, 1986-1990 (1989).

55. G. Novell-Leruth, A. Valcarcel, A. Clotet, J. Ricart, J. Perez-Ramirez, DFT characterization of adsorbed NHx species on Pt(100) and Pt(111) surfaces. Journal of Physical Chemistry B 109, 18061-18069 (2005).

56. M. Bele et al., A highly active PtCu3 intermetallic core-shell, multilayered Pt-skin, carbon embedded electrocatalyst produced by a scale-up sol-gel synthesis. Chemical Communications 50, 13124-13126 (2014).

57. A. Holewinski, S. Linic, Elementary Mechanisms in Electrocatalysis: Revisiting the ORR Tafel Slope. Journal of the Electrochemical Society 159, H864-H870 (2012).

58. E. Coleman, M. Chowdhury, A. Co, Insights Into the Oxygen Reduction Reaction Activity of $\mathrm{Pt} / \mathrm{C}$ and $\mathrm{PtCu} / \mathrm{C}$ Catalysts. Acs Catalysis 5, 1245-1253 (2015).

59. Fuel Cell Technologies Office Multi-Year Research, Developement, and Demonstration Plan (2017).

60. S. Kumar, S. Zou, Electroreduction of O-2 on uniform arrays of Pt and PtCo nanoparticles. Electrochemistry Communications 8, 1151-1157 (2006).

61. M. Nesselberger et al., The effect of particle proximity on the oxygen reduction rate of size-selected platinum clusters. Nature Materials 12, 919-924 (2013). 
62. S. Taylor, E. Fabbri, P. Levecque, T. Schmidt, O. Conrad, The Effect of Platinum Loading and Surface Morphology on Oxygen Reduction Activity. Electrocatalysis 7, 287-296 (2016).

63. M. Jha et al., Hydrometallurgical recovery/recycling of platinum by the leaching of spent catalysts: A review. Hydrometallurgy 133, 23-32 (2013).

64. H. Dong, J. Zhao, J. Chen, Y. Wu, B. Li, Recovery of platinum group metals from spent catalysts: A review. International Journal of Mineral Processing 145, 108-113 (2015). 